\title{
Focus Section on Health IT Usability: Perceived Burden of EHRs on Physicians at Different Stages of Their Career
}

\author{
Saif Khairat ${ }^{1,2}$ Gary Burke $^{3}$ Heather Archambault ${ }^{4}$ \\ ${ }^{1}$ Carolina Health Informatics Program, University of North Carolina, \\ Chapel Hill, North Carolina, United States \\ 2 School of Nursing, University of North Carolina, Chapel Hill, North \\ Carolina, United States \\ ${ }^{3}$ Department of Emergency Medicine, University of North Carolina, \\ Chapel Hill, North Carolina, United States \\ ${ }^{4}$ Department of Biostatistics, University of North Carolina, Chapel \\ Hill, North Carolina, United States \\ ${ }^{5}$ National Center for Human Factors in Healthcare, MedStar Health, \\ Washington, District of Columbia, United States \\ ${ }^{6}$ Georgetown University School of Medicine, Washington, District of \\ Columbia, United States
}

Appl Clin Inform 2018;9:336-347.

\author{
Todd Schwartz ${ }^{4}$ James Larson ${ }^{3}$ Raj M. Ratwani ${ }^{5,6}$
}

Address for correspondence Saif Khairat, PhD, University of North Carolina-Chapel Hill, 428 Carrington Hall, Chapel Hill, NC 27514, United States (e-mail: Saif@unc.edu).

\author{
Abstract \\ Keywords \\ - electronic health \\ records and systems \\ - interfaces and \\ usability \\ - physician \\ - emergency and \\ disaster care \\ - satisfaction
}

Objective The purpose of this study was to further explore the effect of EHRs on emergency department (ED) attending and resident physicians' perceived workload, satisfaction, and productivity through the completion of six EHR patient scenarios combined with workload, productivity, and satisfaction surveys.

Methods To examine EHR usability, we used a live observational design combined with post observation surveys conducted over 3 days, observing emergency physicians' interactions with the EHR during a 1-hour period. Physicians were asked to complete six patient scenarios in the EHR, and then participants filled two surveys to assess the perceived workload and satisfaction with the EHR interface.

Results Fourteen physicians participated, equally distributed by gender (50\% females) and experience (43\% residents, $57 \%$ attendings). Frustration levels associated to the EHR were significantly higher for attending physicians compared with residents. Among the factors causing high EHR frustrations are: (1) remembering menu and button names and commands use; (2) performing tasks that are not straightforward; (3) system speed; and (4) system reliability. In comparisons between attending and resident physicians, time to complete half of the cases as well as the overall reaction to the EHR were statistically different.

Conclusion ED physicians already have the highest levels of burnout and fourth lowest level of satisfaction among physicians and, hence, particular attention is needed to study the impact of EHR on ED physicians. This study investigated key EHR usability barriers in the ED particularly, the assess frustration levels among physicians based on experience, and identifying factors impacting those levels of frustrations. In our findings, we highlight the most favorable and most frustrating EHR functionalities between both groups of physicians. received

November 27, 2017

accepted after revision

March 26, 2018
DOI https://doi.org/

10.1055/s-0038-1648222.

ISSN 1869-0327.
Copyright (๑) 2018 Schattauer

License terms

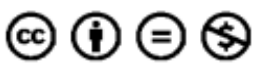




\section{Background and Significance}

The increased adoption of electronic health records (EHRs) has prompted many investigations of their implementation costs and accrued benefits. Hospitals adopting an EHR are more productive, have improved diagnostic accuracy, and have increased quality of care $;^{1-6}$ one study conducted in a single region suggested that an EHR could reduce costs by $\$ 1.9$ million in an emergency department (ED) with an interoperable EHR system. ${ }^{7}$

As EHRs become standard in hospitals, ease of usabilitythe facility with which a user can accurately and efficiently accomplish a task-has gained increased attention. ${ }^{8,9}$ Many deficiencies exist in EHR usability, such as human errors as a result of poor interface design (i.e., when clinicians' needs are not taken into account, or the information display does not match user workflow). ${ }^{10-13}$ Other usability challenges exist, such as limitations to a user's ability to navigate an EHR, enter information correctly, or extract information necessary for task completion. For EHRs to be effective in assisting with clinical reasoning and decision-making, they should be designed and developed with consideration of physicians, their tasks, and their environment. ${ }^{14}$

Physicians may approve of EHRs in concept and appreciate the ability to provide care remotely at a variety of locations; however, in an assessment of physicians' opinions of EHR technologies in practice, the American Medical Association (AMA) found that EHRs significantly eroded professional satisfaction: $42 \%$ thought their EHR systems did not improve efficiency, and $72 \%$ thought EHR systems did not improve workload. ${ }^{15}$ In an Association of American Physicians and Surgeons (AAPS) survey, more than half of physicians felt burned out from using EHRs, ${ }^{16}$ and emergency medicine physicians spent almost half their shift on data entry, with 4,000 EHR clicks per day. ${ }^{17}$ In a survey of 1,793 physicians, Jamoom et al found that more than $75 \%$ of physicians reported that EHR increases the time to plan, review, order, and document care. ${ }^{18}$ Physician frustration is associated with lower patient satisfaction and negative clinical outcomes. ${ }^{19-21}$

EHR dissatisfaction among physicians may be damaging to medicine. ${ }^{15,22}$ Providing care in the era of EHRs leads to high level work-related stress and burnout among physicians; ${ }^{23} \mathrm{ED}$ physicians specifically already have the highest levels of burnout and fourth lowest level of satisfaction among physicians. Particular attention, then, is needed to examine the impact of using an EHR on ED physicians. ${ }^{24}$ Increasing age among physicians were negatively correlated with EHR adoption levels; ${ }^{25}$ however, only modest, if any, attempts have been made to understand if reported usability dissatisfaction levels will decrease with the changing of the guard, that is, as younger physicians with lifetime experience using information technologies develop and mature in the medical profession.

\section{Objective}

The purpose of this study was to explore the effect of EHRs on ED attending and resident physicians' perceived workload, satisfaction, and productivity through the completion of six
EHR patient scenarios combined with workload, productivity, and satisfaction surveys. We hypothesized that attending physicians-who are traditionally older, more experienced, and further removed from and/or lacking medical training with robust EHR integration-would be more frustrated with the EHR compared with resident physicians. We hypothesized that the latter would have more training using and experience with EHRs and, thus, be more comfortable with the electronic platforms.

\section{Methods}

\section{Study Design}

To examine EHR usability, we used a live observational design combined with immediate postobservation surveys conducted over 3 days, observing emergency physicians' interactions with the EHR during a 1-hour period. We created six EHR patient scenarios in the training environment of a commercial EHREpic version 2014-to mimic standard ED cases.

\section{Participants and Setting}

We conducted the study at a large, tertiary academic medical center. We recruited emergency medicine attending physicians ("attendings"; $n=8$ ) and resident physicians ("residents"; $n=6$ ) in their third and fourth years in training to participate in this study, which took place in the Emergency Medicine Department office space. Participants sat in a private office equipped with a workstation and interacted with the training environment of Epic 2014 used at that medical center. At the time of the study, all participants used Epic 2014 to deliver care with varying degrees of exposure to the EHR. We obtained Institutional Review Board approval. All participants were given an information sheet-describing the study procedure and objective, time commitment, and compensation, and had an opportunity to ask questions. We obtained verbal consent for participation in the study as well as for the participant to be video recorded.

\section{Procedure}

Our research team comprised two investigators with $\mathrm{PhDs}$ in health informatics and health services, one research coordinator for usability services, a project manager on human factors, and an ED physician. We designed six patient cases that were incorporated into the training environment of the Epic 2014 system used by the hospital. An EHR expert consultant from the hospital team-an Epic builder with a nursing background-created a patient record in the EHR for each of the six cases, entering information about each patient (e.g., name, date of birth (DOB), height, weight, chief complaint, triage note, vital signs, history of present illness, pertinent exam, past medical history, medications, allergies, social history). For each patient record, the team designed a case scenario for participants to follow and execute in the EHR. The study sessions were conducted separately for each participant in a clinical simulation setting.

We asked participants to complete the six comprehensive ED scenarios that included tasks to ensure that participants were exposed to various aspects of the EHR. Every participant 
had an hour to complete all six scenarios sequentially and was expected to approach each scenario with similar thoroughness, which was evaluated by successful task completion. We conducted the study in a simulated setting to minimize bias; all participants were presented with the same scenarios in the same environment on days during which they did not have scheduled work. First, participants identified the fictitious patients' cases in the EHR. Next, a research assistant read the scenarios, which included a set of initial actions and evaluations, follow-up actions, and disposition, which the participants were to complete in the EHR. Participants could make handwritten notes about the scenario, actions, and disposition. During the encounter, participants could ask the research assistant to repeat the scenario or task as needed.

We measured how managing six different EHR scenarios affected user experience and satisfaction (-Table 1). We designed the patient cases to include common EHR challenges such as cognitive overload, patient safety and medication errors, and information management and representation; furthermore, we designed the patient cases to reflect standard EHR tasks done by ED physicians ( - Table 1).

Following completion of the six scenarios, we asked participants to complete two survey questionnaires: the National Aeronautics and Space Administration Task Load Index (NASA-TLX) (-Appendix Fig. A1) and Questionnaire for User Interaction Satisfaction (QUIS).

\section{Measurement}

We recorded usability data, including time to complete a task with usability software Morae Recorder (Okemos, Michigan, United States) installed on the study workstation. The user experience surveys, TLX and QUIS, were administered immediately following the EHR testing sessions to evaluate the user's perception of the EHR experience and the EHR interface design.

The TLX is a selective workload assessment tool of human-computer interface designs measuring users' perceived workload levels in six dimensions: mental demand, physical demand, temporal demand, performance, effort, and frustration. ${ }^{26,27}$ Each dimension is ranked on a 20-step bipolar scale, with scores ranging from 0 and 100 . The scores for all dimensions then are combined to create an overall workload scale (0-100). The QUIS assesses users' subjective satisfaction with specific aspects of the human-computer interface. ${ }^{28}$ According to the Agency for Healthcare Research and Quality (AHRQ), the QUIS is valid even with a small sample size, and provides useful feedback of user opinions and attitudes about the system, ${ }^{29}$ specifically about the usability and user acceptance of a human-computer interface. The tool contains a demographic questionnaire; a measure of overall system satisfaction along five subscales: overall reaction, screen factors, terminology and system feedback, learning factors, and system capabilities; as well as open-ended questions about the three most positive and negative aspects of the system. Each area subscale measures the users' overall satisfaction with that facet of the interface, as well as the factors that make up that facet, on a 9-point scale. A detailed description of the QUIS tool and evaluation items is shown in - Table 2.
Table 1 Study scenarios, EHR function, and built-in usability issues

\begin{tabular}{|c|c|}
\hline Cases & EHR function \\
\hline \multirow{4}{*}{$\begin{array}{l}\text { 1. Pediatric } \\
\text { forearm } \\
\text { fracture }\end{array}$} & 1. Method of calculating dosing \\
\hline & 2. How physician refers to patient weight \\
\hline & 3. Process of ordering morphine \\
\hline & 4. Process of ordering facility transfer \\
\hline \multirow{4}{*}{$\begin{array}{l}\text { 2. Back } \\
\text { pain }\end{array}$} & 1. EHR clinical support \\
\hline & 2. Process of ordering MRI \\
\hline & 3. Discharge process \\
\hline & $\begin{array}{l}\text { 4. Time sensitive protocol but } \\
\text { not easily ordered }\end{array}$ \\
\hline \multirow[t]{4}{*}{$\begin{array}{l}\text { 3. Chest } \\
\text { pain }\end{array}$} & $\begin{array}{l}\text { 1. Situational awareness (How will } \\
\text { physician relay need to monitor } \\
\text { patient blood pressure?) }\end{array}$ \\
\hline & $\begin{array}{l}\text { 2. How does physician view patient's } \\
\text { blood pressure }\end{array}$ \\
\hline & $\begin{array}{l}\text { 3. Process of ordering test to be } \\
\text { completed at future time }\end{array}$ \\
\hline & $\begin{array}{l}\text { 4. Process of admitting patient for } \\
\text { telemetry }\end{array}$ \\
\hline \multirow{4}{*}{$\begin{array}{l}\text { 4. Abdominal } \\
\text { pain }\end{array}$} & 1. Process of ordering specific CT scan \\
\hline & 2. Process of reviewing CT Scan \\
\hline & 3. Process of discharge \\
\hline & 4. Ordering over $4-6$ h \\
\hline \multirow[t]{3}{*}{ 5. Asthma } & $\begin{array}{l}\text { 1. Process of delivering nebulizer } \\
\text { treatment }\end{array}$ \\
\hline & 2. Process of ordering medication taper \\
\hline & 3. Is SureScripts system tied in \\
\hline \multirow[t]{4}{*}{ 6. Sepsis } & $\begin{array}{l}\text { 1. Process of renal dosing for } \\
\text { appropriate antibiotics }\end{array}$ \\
\hline & $\begin{array}{l}\text { 2. Process of ordering weight based fluids, } \\
\text { how does system calculate (if at all) }\end{array}$ \\
\hline & $\begin{array}{l}\text { 3. Process of ordering laboratories to } \\
\text { be completed at future time }\end{array}$ \\
\hline & $\begin{array}{l}\text { 4. Does EHR provide guidance on } \\
\text { appropriate rate of medication }\end{array}$ \\
\hline
\end{tabular}

Abbreviations: $\mathrm{CT}$, computed tomography; EHR, electronic health record; MRI, magnetic resonance imaging.

\section{Statistical Analysis}

Using SAS software, version 9.4 (Cary, North Carolina, United States), data were analyzed using descriptive statistics (means and standard deviations for continuous variables; frequencies and percentages for categorical variables). Bivariate associations were computed for pairs of continuous variables via Pearson's correlation coefficients. Means were compared between groups and via two-sample Satterhwaite t-tests, separately by gender, role (attending physician vs. resident physician), and hours working in the ED (low vs. high). Although hours working in the ED was captured as a continuous variable, we dichotomized the variable as "low" for residents who worked 50 or fewer hours per week or for attendings who worked 30 or fewer hours, and as "high" for 
Table 2 QUIS tool subscales and the corresponding items to be evaluated

\begin{tabular}{|c|c|c|}
\hline QUIS & Description & Evaluations Items \\
\hline $\begin{array}{l}\text { Overall reaction } \\
\text { to the EHR }\end{array}$ & $\begin{array}{l}\text { Users assess the overall user experience with the } \\
\text { EHR. }\end{array}$ & $\begin{array}{l}\text { - Navigation } \\
\text { - Satisfaction } \\
\text { - Power } \\
\text { - Stimulation }\end{array}$ \\
\hline Screen & Users rate the screen/interface design of the EHR & $\begin{array}{l}\text { - The ability to read characters on the screen } \\
\text { - Information overload } \\
\text { - Organization of information } \\
\text { - Sequence of screens }\end{array}$ \\
\hline $\begin{array}{l}\text { Terminology and } \\
\text { system information }\end{array}$ & $\begin{array}{l}\text { Users rate the consistency of terminology, } \\
\text { frequency and clarity of hard stops, and system } \\
\text { feedback on tasks }\end{array}$ & $\begin{array}{l}\text { - Use of terms through the system } \\
\text { - Terminology related to task } \\
\text { - Position of message on screen } \\
\text { - Prompts for input } \\
\text { - Computer informs about its progress } \\
\text { - Error messages }\end{array}$ \\
\hline Learning & $\begin{array}{l}\text { Users evaluate their ability to use the system, the } \\
\text { effort and time to learn the system, knowledge on } \\
\text { how to perform tasks, and the availability of } \\
\text { support }\end{array}$ & $\begin{array}{l}\text { - Learning to operate the system } \\
\text { - Exploring new features by trials and error } \\
\text { - Remembering names and use of commands } \\
\text { - Performing tasks is straightforward } \\
\text { - Help messages on the screen } \\
\text { - Supplemental reference materials }\end{array}$ \\
\hline System capability & $\begin{array}{l}\text { Users rate the performance and usability of the } \\
\text { EHR }\end{array}$ & $\begin{array}{l}\text { - System speed } \\
\text { - System reliability/System down } \\
\text { - Ability to correct mistakes } \\
\text { - System designed for all levels of users }\end{array}$ \\
\hline
\end{tabular}

Abbreviations: EHR, electronic health record; QUIS, Questionnaire for User Interaction Satisfaction.

residents who worked more than 50 hours or for attendings who worked more than 30 hours, based on ED physician expert suggestion. We used a two-sided significance level of 0.05 and did not adjust $p$-values for multiple comparisons.

\section{Results}

Fourteen physicians participated, equally distributed by gender (50\% female) and experience (43\% residents, $57 \%$ attendings) ( - Table 3 ). All residents had no postresidency clinical practice experience whereas the attendings had 3 or more years of clinical experience since residency; however, $75 \%$ of each groups had 3 to 5 years or $>5$ years of experience using Epic prior to the study. Residents worked in the ED for an average of $54.2 \pm 3.7$ hours per week, and attendings for $27.5 \pm 7.2$ hours per week. The physicians, when not divided by classification, achieved a mean TLX score of $6.3 \pm 2.3$ out of 20. Participants took an average of $21.7 \pm 7.0$ minutes to finish all six scenarios, with completion times ranging from 12.6 to 36.3 minutes.

\section{Perceived Workload in the EHR}

In two-sample $t$-tests comparing differences for the NASATLX total score and its items by role (resident vs. attendings), by gender, and by category of hours worked, we found only one significant difference: the frustration item was significantly lower for residents than for attendings (3.3 vs. 8.0, $p<0.01$ ) (-Fig. 1).

Bivariate associations between the TLX total score and the QUIS items are shown in - Table 4. The TLX total score was significantly correlated with the screen item (Pearson's $r=0.62, p=0.02$ ), such that higher ratings on the screen were associated with higher TLX total scores. No other significant correlations were found for any TLX item with the QUIS ratings.

\section{EHR Satisfaction}

We found significant correlations among the NASA-TLX and the QUIS survey results ( - Table 4). All participants completed both surveys and data were matched using an assigned unique participant identifier. Higher overall reaction, measured by evaluating navigation, satisfaction, power, and stimulation, was associated with higher ratings for terminology and information $(r=0.54, p<0.05)$ and with lower times to completion of all scenarios $(r=-0.73, p<0.01)$. Higher system capability ratings were associated with higher ratings for the screen item $(r=0.60, p=0.02)$ and with higher learning ratings $(r=0.80, p<0.01)$. Also, higher terminology and information ratings were positively associated with higher learning ratings $(r=0.62, p=0.02)$. Although not statistically significant, higher ratings of the system capabilities tended to yield shorter times to completion of all scenarios $(r=-0.44)$.

Pearson's correlation coefficients were determined for frustration with each individual QUIS score, - Table 5. Within the context of learning the system, lower scores for remembering commands and for performing straightforward tasks were associated with greater frustration with the system. Within the items describing system capabilities, lower scores for system speed and for system reliability were also significantly associated with greater frustration with the system. 
Table 3 Demographics

\begin{tabular}{|c|c|c|c|c|c|}
\hline & & \multicolumn{2}{|l|}{ Resident, $n$ (\%) } & Attending, $n(\%)$ & Total \\
\hline \multirow[t]{2}{*}{ Gender } & Male & \multicolumn{2}{|l|}{$5(83.3)$} & $2(25)$ & 7 \\
\hline & Female & \multicolumn{2}{|l|}{$1(16.7)$} & $6(75)$ & 7 \\
\hline \multirow[t]{3}{*}{ Age } & $18-34$ & \multicolumn{2}{|l|}{$6(100)$} & 0 & 6 \\
\hline & $35-50$ & \multicolumn{2}{|l|}{0} & $7(87.5)$ & 7 \\
\hline & $51-69$ & \multicolumn{2}{|l|}{0} & $1(12.5)$ & 1 \\
\hline \multirow[t]{2}{*}{ Ethnicity } & Asian & \multicolumn{2}{|l|}{0} & $1(12.5)$ & 1 \\
\hline & White & \multicolumn{2}{|l|}{$6(100)$} & $7(87.5)$ & 13 \\
\hline \multirow{4}{*}{\multicolumn{2}{|c|}{$\begin{array}{l}\text { Years of clinical practice } \\
\text { (postresidency): }\end{array}$}} & 0 & $6(100)$ & 0 & 6 \\
\hline & & $1-2 y$ & 0 & 0 & 0 \\
\hline & & $3-5 y$ & 0 & $2(25)$ & 2 \\
\hline & & More than $5 \mathrm{y}$ & 0 & $6(75)$ & 6 \\
\hline \multirow{3}{*}{\multicolumn{2}{|c|}{$\begin{array}{l}\text { Number of years of } \\
\text { experience in Epic prior to } \\
\text { the study }\end{array}$}} & $1-2 y$ & $1(25)$ & $2(25)$ & 3 \\
\hline & & $3-5 y$ & $5(75)$ & $5(62.5)$ & 10 \\
\hline & & $>5 y$ & 0 & $1(12.5)$ & 1 \\
\hline \multirow{3}{*}{\multicolumn{2}{|c|}{$\begin{array}{l}\text { Average number of hours } \\
\text { worked in Epic per week }\end{array}$}} & $<30 \mathrm{~h}$ & 0 & $6(75)$ & 6 \\
\hline & & $30-50 \mathrm{~h}$ & $2(50)$ & $2(25)$ & 4 \\
\hline & & $>50 \mathrm{~h}$ & $4(50)$ & 0 & 4 \\
\hline \multicolumn{3}{|l|}{ Total } & 6 & 8 & 14 \\
\hline
\end{tabular}

\section{EHR Productivity}

Furthermore, in comparisons between resident and attending physicians, time to complete the back pain, chest pain, and sepsis scenarios, as well as overall reaction (based on QUIS scores), were statistically different (-Fig. 2). In comparisons between high and low average numbers of hours worked, the time to complete the sepsis scenario and overall reaction showed significant differences (-Fig. 2).

-Fig. 2 shows separate assessments for each scenario made via Satterthwaite $t$-tests by role (resident vs. attending). Residents had significantly shorter mean durations to complete the back pain (1.9 vs. 3.0 minutes, $p<0.01$ ), chest

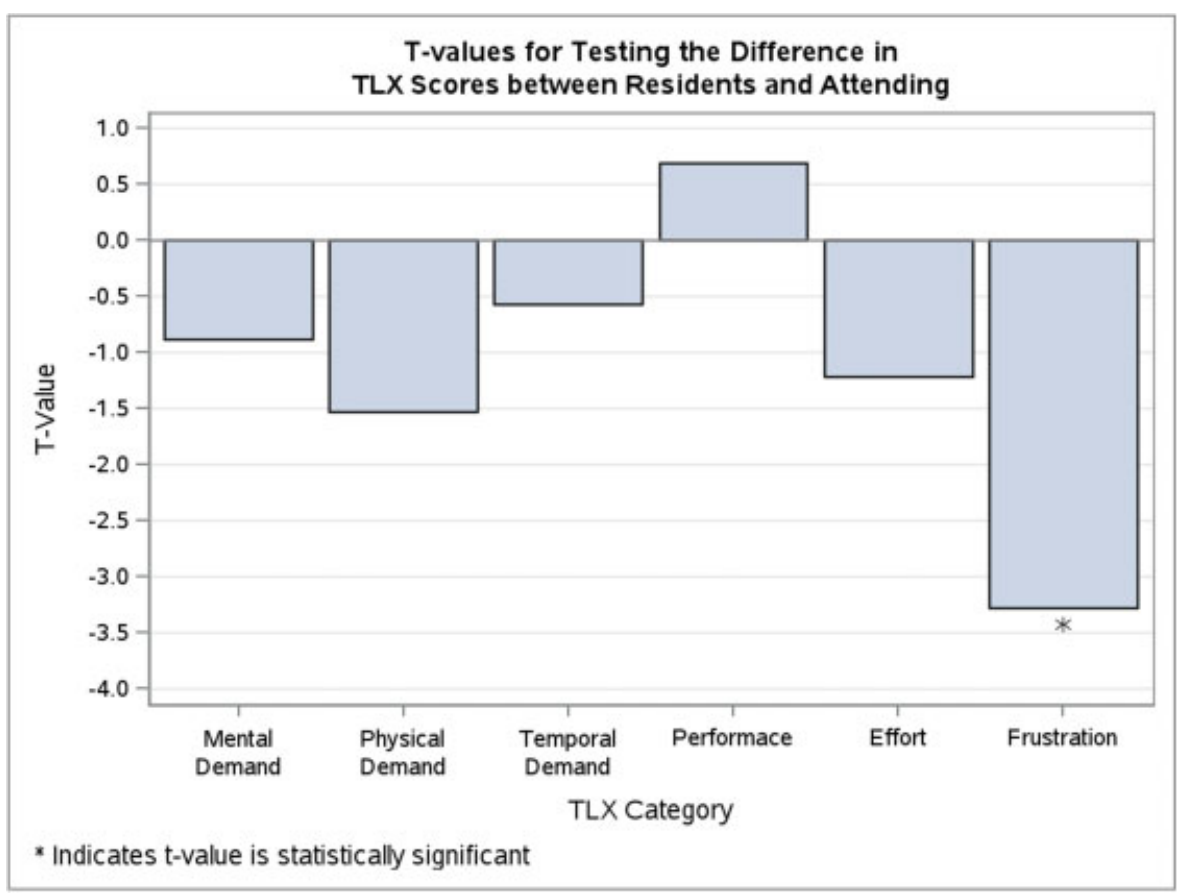

Fig. 1 -Values for testing the difference in Task Load Index (TLX) scores between residents and attending. 
Table 4 Correlation coefficients and p-Values (bold) between NASA-TLX and QUIS items

\begin{tabular}{|l|l|l|l|l|}
\hline & Overall reaction & Screen & Terminology and information & Learning \\
\hline Terminology and information & 0.538 & 0.333 & $\mathrm{NA}$ & \\
& $\mathbf{0 . 0 4 7 ^ { \mathrm { a } }}$ & $\mathbf{0 . 2 4 5}$ & & \\
\hline Learning & 0.440 & 0.314 & 0.616 & $\mathrm{NA}$ \\
& $\mathbf{0 . 1 1 5}$ & $\mathbf{0 . 2 7 4}$ & $\mathbf{0 . 0 1 9 ^ { \mathrm { a } }}$ & \\
\hline System capabilities & 0.336 & 0.600 & 0.374 & 0.805 \\
& $\mathbf{0 . 2 4 0}$ & $\mathbf{0 . 0 2 3 ^ { \mathrm { a } }}$ & $\mathbf{0 . 1 8 8}$ & $\mathbf{0 . 0 0 1 ^ { \mathrm { a } }}$ \\
\hline Total number of minutes to & -0.725 & -0.395 & -0.324 & -0.291 \\
complete all scenarios & $\mathbf{0 . 0 0 3 ^ { \mathrm { a } }}$ & $\mathbf{0 . 1 6 2}$ & $\mathbf{0 . 2 5 9}$ & $\mathbf{0 . 3 1 2}$ \\
\hline
\end{tabular}

Abbreviations: NASA-TLX, National Aeronautics and Space Administration Task Load Index; QUIS, Questionnaire for User Interaction Satisfaction. a Statistically significant values.

Table 5 Correlation coefficients and p-Values (bold) between frustration levels and EHR characteristics

\begin{tabular}{|l|l|l|l|l|}
\hline & $\begin{array}{l}\text { Remembering names } \\
\text { and commands use }\end{array}$ & $\begin{array}{l}\text { Performing tasks is } \\
\text { straightforward }\end{array}$ & $\begin{array}{l}\text { System } \\
\text { speed }\end{array}$ & $\begin{array}{l}\text { System } \\
\text { reliability }\end{array}$ \\
\hline Frustration levels & -0.555 & -0.600 & -0.709 & -0.633 \\
& $0.039^{\text {a }}$ & $0.023^{\text {a }}$ & $0.004^{\text {a }}$ & $0.015^{\text {a }}$ \\
\hline
\end{tabular}

Abbreviation: EHR, electronic health record.

a Statistically significant values.

pain (2.4 vs. 4.7 minutes, $p<0.01$ ), and sepsis (2.0 vs. 3.7 minutes, $p<0.01$ ) scenarios compared with attendings. Although not statistically significant, residents also took less time, on average, to complete the abdominal pain scenario (2.3 vs. 3.2 minutes). - Fig. 2 also shows results of twosample $t$-tests demonstrating significant differences for the QUIS items by role (resident vs. attending). When examining by role, the mean score for overall reaction was significantly higher for residents than for attendings ( $7.1 \mathrm{vs.} 5.8, p=0.02$ ).
Comparisons by hours worked in the EHR indicated that those working fewer hours took a significantly longer time to complete the sepsis and back pain scenarios compared with those working more hours (3.4 vs. 2.3 minutes, $p<0.05$, and 2.9 vs. 2.1 minutes, $p=0.05$ ). Although not statistically significant, -Fig. 3 show that the same pattern was demonstrated for the abdominal pain ( 3.2 vs. 2.3 minutes), and chest pain ( 4.4 vs. 2.8 minutes, $p=0.09$ ) scenarios. By hours worked, overall reaction ratings were significantly lower for

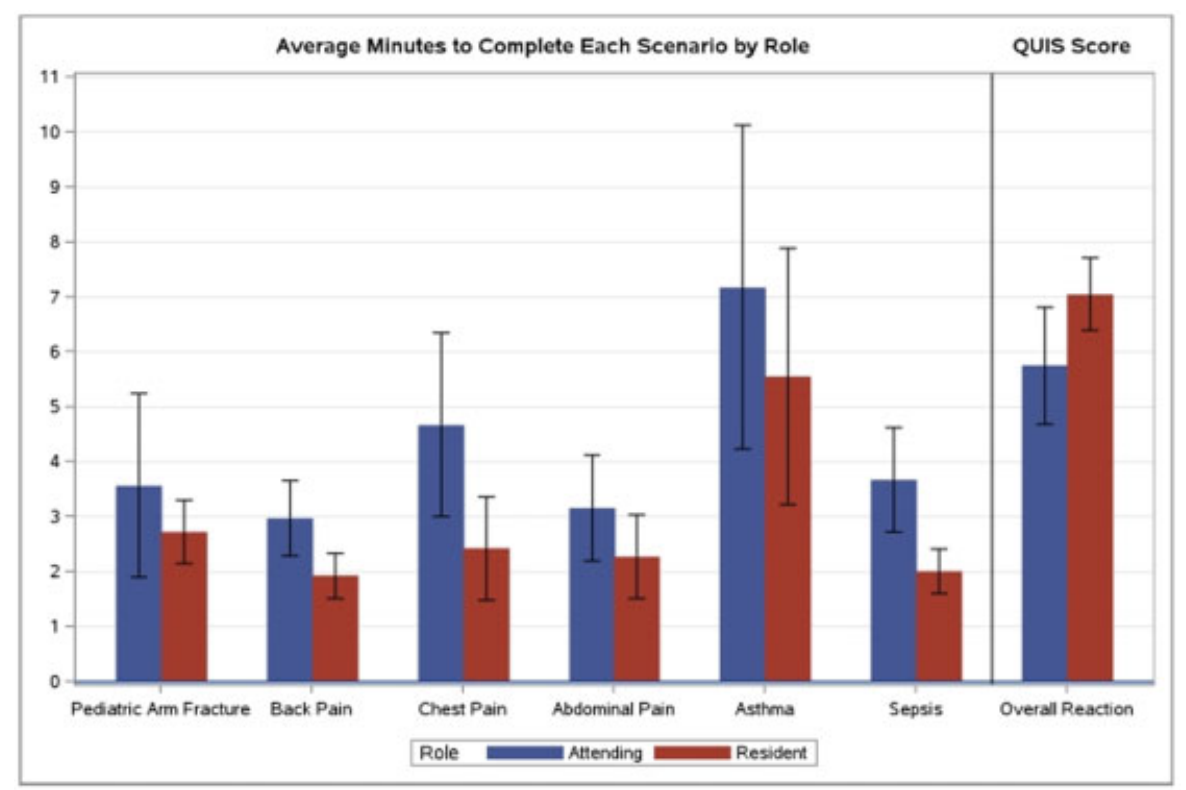

Fig. 2 Average minutes to complete each scenario by role. 


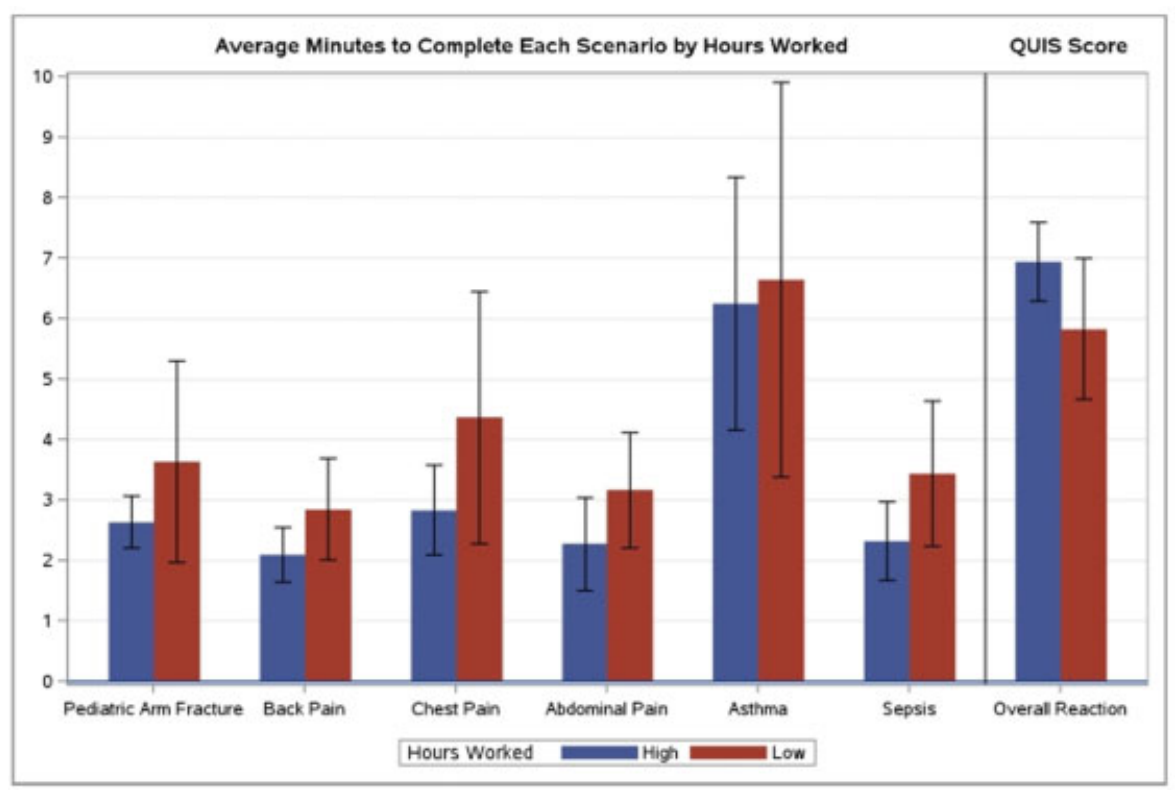

Fig. 3 Average minutes to complete task by electronic health record (EHR) hours worked. Difference in satisfaction levels based on EHR hours worked.

those working fewer hours (5.8 vs. 6.9, $p<0.05)$ than for those working more hours.

\section{EHR Preferences and Frustrations}

To understand differences in EHR preferences and frustrations, participants were asked at the end of the exercise on the QUIS survey to identify the three most favorable and most frustrating functions of the EHR; 12 (85\%) participated and were equally distributed between roles. Common preferences emerged among both groups, such as appreciation for "click" shortcuts available when placing an order, and the ability to autopopulate smart phrases in the notes by using the dot (.) phrases functionality. Two-thirds of attending complimented the EHR design, noting its reactive speed as well as its clean, consistent, and reliable layout. Residents particularly liked the flexibility for care through EHR access at multiple sites. Residents also expressed satisfaction in the comprehensive and consolidated representation of patient information (-Fig.4).

With regard to frustrations, attending complained about the frequency and rationale behind warnings and errors messages, such as alerts when ordering tests, medication, or computed tomography (CT) for patients with allergies.

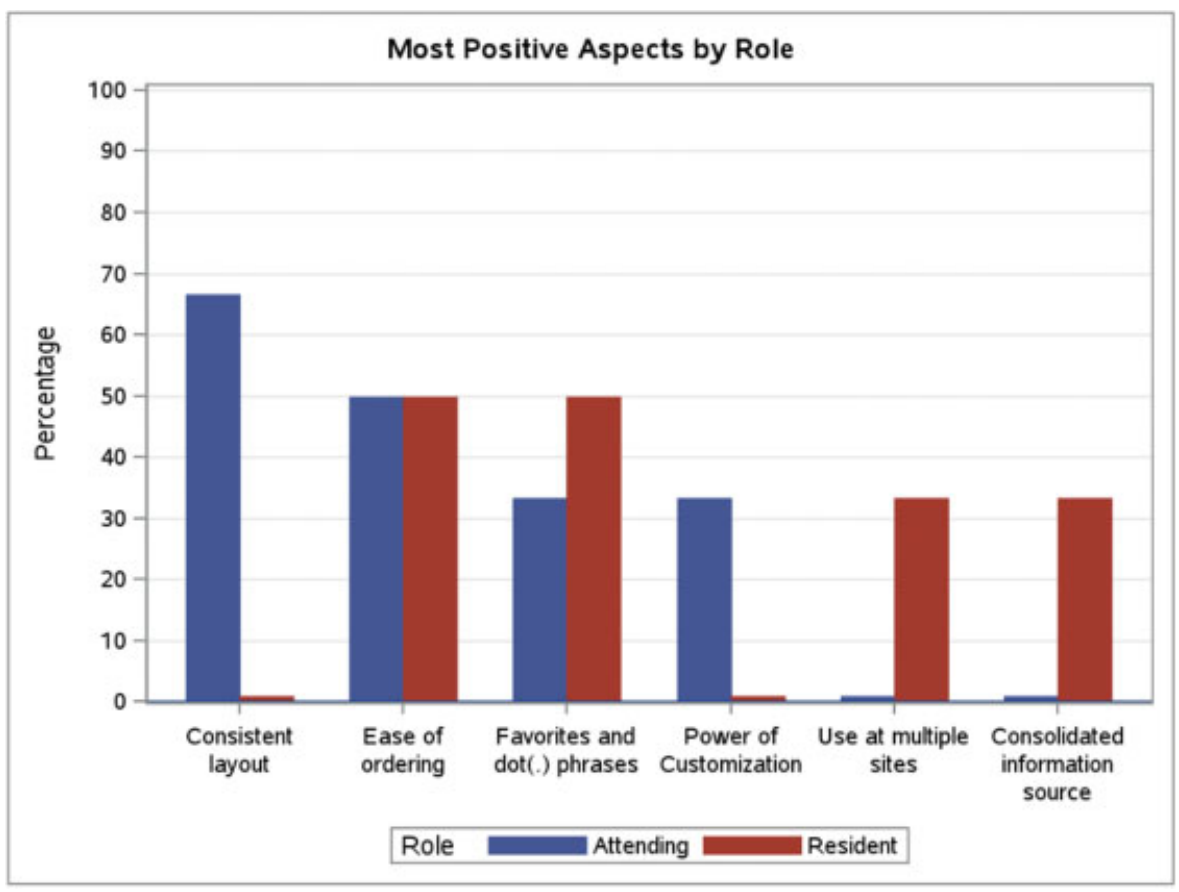

Fig. 4 Most positive aspects of the electronic health record (EHR) by roles. 


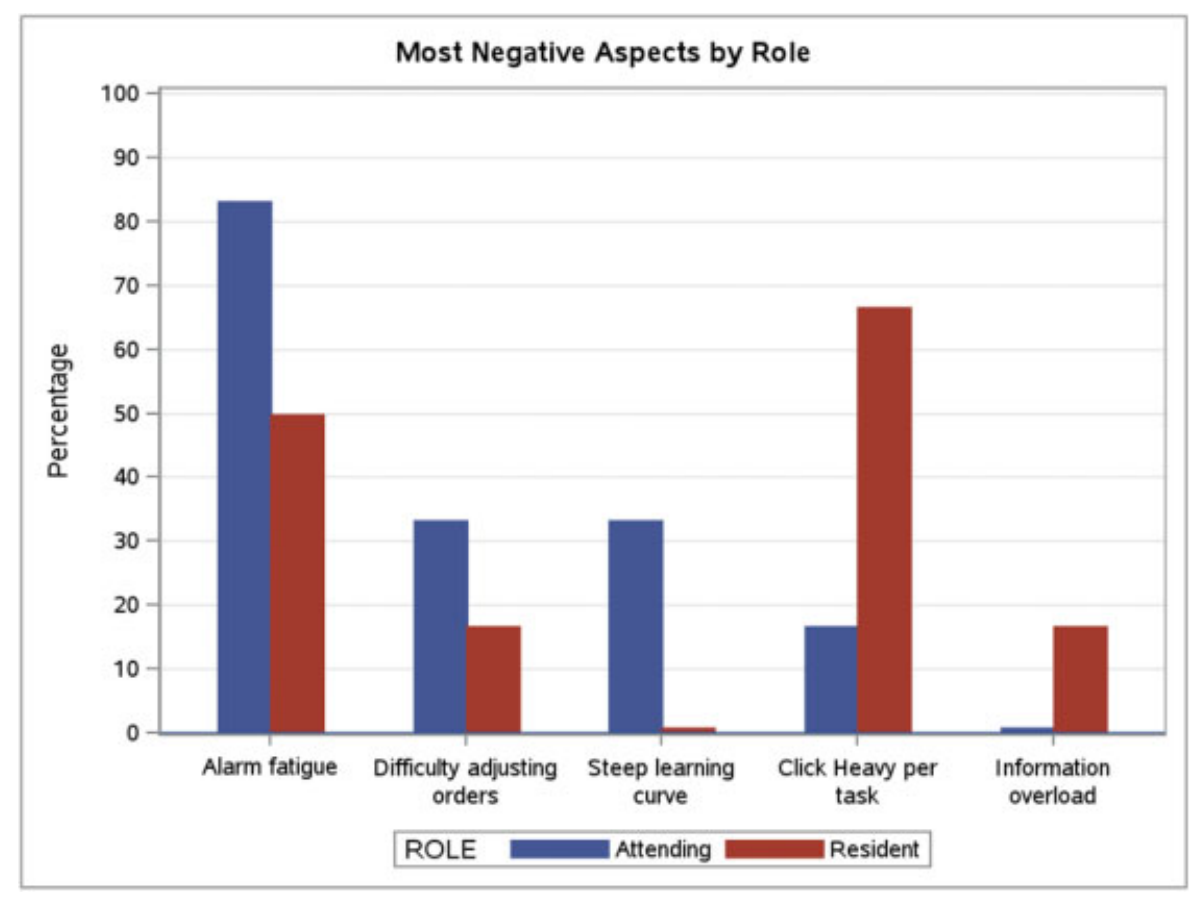

Fig. 5 Most negative aspects of the electronic health record (EHR) by roles.

While half of the attendings found it easy to place orders, one-third found it difficult to adjust orders once placed. Attendings also expressed concern about the steep learning curve associated with the EHR, which they often found to be mentally taxing. Residents' main complaints were with the number of mouse clicks per task in the EHR. Like attendings, residents noted that orders were difficult to adjust once placed, and that alert fatigue remains a significant challenge of EHR use. Residents were also dissatisfied with information overload when reviewing patient charts ( - Fig. 5 ).

\section{Discussion}

We found in this study a significant disparity between overall satisfaction with the EHR between residents and attending physicians. Attending reported significantly higher frustration levels with the EHR. This difference may be explained by the time it took for participants to complete the six scenarios: residents completed half the scenarios significantly faster than attending. Aside from computer skills, longer completion times may be attributed to attending physicians' wider repertoire of clinical experience and judgment, and hence, attendings may look for more patient data and consider alternate explanations more than residents. As a result, attendings may take longer to complete a task if more data are required to make clinical judgment. We raise the question of whether shorter completion time is actually a valid indication of better usability, and what is the effect of faster interaction on clinical outcomes. A quicker completion time that is free of errors yet maintains thoroughness would be ideal; nonetheless, this is a topic that should be explored and evaluated in future work.

The workflow discrepancy between a resident and an attending must also be considered. At many institutions, particularly academic ones, the attendings' responsibilities are often supervisory, while residents do much of the work of documentation including entering orders and notes. Attending physicians oversee and supplement direct patient care and documentation. Attending ultimately sign off on documentation completed by a resident; nonetheless, if residents are performing most of the work of order entry and making clinical notes, they may be more comfortable with EHRs and, thus, quicker to complete the scenarios compared with their attending physicians.

The EHR screen design showed a significant relationship with effort exerted to find information, temporal demand levels, and overall perceived workload. Most participants noted a relationship between screen design and how much effort they spent on a task. They tended to be satisfied if the design did not require much effort to interact with it. Finally, we found a relationship between the physician's EHR experiences (i.e., number of hours spent working with the EHR) and the reported levels of satisfaction among physicians: the attending, on average, work $<50$ hours per week with Epic, whereas their resident counterparts work 30 to 50 hours $(50 \%)$ or $>50$ hours ( $50 \%$ ) weekly with Epic ( - Table 3 ). This, coupled with the significantly higher mean score for overall reaction for residents (7.1 vs. 5.8, $p=0.02$ ), indicate that the physicians who spent more time working on the EHR reported higher levels of satisfaction.

Our results showed that participants were satisfied with the broad array of functions provided through the system; however, our findings indicated that a significant learning curve was required to learn ways to navigate the system. Participants ranked the mental demand as the highest perceived EHR workload, and the physical demand as the lowest. Participants rated aspects of the EHR interface design such that system 
capabilities were the highest category in terms of satisfaction, while learning factors was the lowest ranked category. On average, participants completed six scenarios in 21 minutes; however, there was a range of 7 minutes among participants.

We found a concerning disconnection between the theory behind EHR systems and the reality of using them in practice. EHRs were designed to make the administration of medical care easier for physicians and safer for patients ${ }^{30}$ but frustrations with technology have, in many cases, had the opposite effect. Physician frustration with the EHR has been associated with high burnout levels, lower patient satisfaction, and negative clinical outcomes. ${ }^{19-21}$ For instance, in 2013, a 16-year-old boy received more than 38 trimethoprim/sulfamethoxazole (trade name Septra, Bactrim) tablets while hospitalized. ${ }^{31}$ Poor interface design within an EHR system was ultimately blamed for the massive antibiotic overdose, which was nearly fatal for the young patient. The aforementioned impact of poor interface design and human factors is not unique to health care; human factors in other disciplines have shown critical and fatal errors as a result of lack of user-center interface design. For example, the famous Canada Air incident named Gimli Glider shows the importance of human-computer interaction when an accident occurred due to a pilot error with the cockpit Fuel Quantity Indicator System (FQIS). ${ }^{32}$ Similarly, human factors research have demonstrated similar results with regards to the relationship between interface designs and complex systems usability in fields like aviation, psychology, education, and computer science. ${ }^{33-35}$ The usability findings in this article aligns with findings in similar disciplines. For instance, in aviation workers are under extreme stress while attempting to access considerable amounts of data. Information overload, a contributing factor to degraded decision making ability, affects these works by introducing delay in the correct response. ${ }^{36}$

To improve EHR usability, we need to assess and address user "personas" that take into account users' clinical experience as well as their technical abilities. Tailoring the EHR interface by clinical roles (e.g., nurse, program coordinator, and physician) is insufficient: rather, we should specify the individual personas associated with each clinical role. Personas are used to create realistic representations of key users; it is commonly used in disciplines such as marketing, information architecture, and user experience. ${ }^{37-40}$ The interface needs to be tailored to the different personas within the same role. For example, attending physicians are domain experts who may have received their medical training prior to EHR adoption and, therefore, their expectations of the EHR will be different than a resident who has been training post-EHR adoption. This study shows that not all physicians are dissatisfied with the EHR and that there are varying levels of satisfaction based on seniority. Our results show that attending physicians are notably more frustrated than resident physicians when using the EHR. We expect that levels of frustration from the EHR among providers may diminish as the careers advance of more physicians who have life-long exposure to information technologies. To meet the expectations of all users, however, current EHR designs require major revisions with input from a range of clinicians with varying degrees of roles and experience and expertise with the electronic platforms.

Although the simulation-based environment we used in this research served the purpose of understanding the perceived workload and satisfaction of ED physicians regarding EHRs, we also noted limitations. Conducting the study in the ED in real-time hold potential to reveal new patterns and create different outcomes for the time to task completion, perceived workload, and satisfaction due to the intensity and interruptions inherent in the ED environment; however, the ability to implement such a study in real-life settings is challenging for several reasons. First, the risk of disclosing protected patient information is significant. Second, providing a survey at the end of a physician's ED shift may introduce bias related to fatigue or salience of the records of last few patients seen.

Finally, the number of participants ( 8 physicians and 6 resident physicians) may be viewed as a limitation related to the lack of statistical power in the analysis; however, five participants are usually sufficient for usability studies such as this one. ${ }^{41}$

Researchers and scientists in fields other than health care developed the TLX and QUIS, therefore these tools are not specifically designed to assess EHR interfaces. We suggest that future efforts should include developing tailored and validated qualitative and quantitative tools to assess the usability of the health information technology applications used by health care providers and researchers.

Furthermore, the use of eye-tracking methodologies has shown promise in the sociobehavioral and engineering fields. ${ }^{42-44}$ However, despite modest attempts to build a framework explaining how to use eye-tracking devices in health services research, in particular, ways to integrate eyetracking into a study design, there remains a need for a health-specific manual explaining how to use the said devices. In order for them to best benefit medical research, formal training for medical personnel must occur. ${ }^{45,46}$ Importantly, this effort would contribute to the development of creative ways of analyzing the large data files provided by the eye-tracker using automation and algorithms.

\section{Conclusion}

In this article, we presented findings from an EHR usability study of physicians in the emergency medicine department at a tertiary academic medical center. Although this study builds on previous research, ${ }^{16,18,47}$ it differs from previous work because we focused on responses to EHR, especially frustration, between physicians at two different career levels, and the factors leading to frustration. We found that EHR frustration levels are significantly higher among more senior attending physicians compared with more junior resident physicians. Among the factors causing high EHR frustrations are: (1) remembering menu and button names and commands use; (2) performing tasks that are not straightforward; (3) system speed; and (4) system reliability.

In our findings, we highlight the most favorable and most frustrating EHR functionalities of both groups of physicians. 
Attending physicians appreciate the consistency in EHR user interface and the ease of entering orders in the system, and they reported frustrations with the frequency of hard stops in the system. Although residents appreciated the ability to use dot phrases and autocomplete functions, as well as the ease of entering orders, they found the click-heavy and alert fatigue aspects of EHR to be most frustrating.

The findings of this study can be used to inform future usability studies, in particular, more specific usability areas such as information representation, standardized pathways to accomplishing tasks, and ways to reduce the steep learning curve for users. Finally, today's resident physicians will become tomorrow's attending physicians, faced with new duties or demands. In this never-ending technological cycle, the only certainty is that nothing stays the same. More research is needed to investigate ways to improve satisfaction with the EHR through meeting the various expectations from techsavvy residents to domain expert attending physicians.

\section{Clinical Relevance Statement}

Electronic health records may lead to higher physician's burnout and dissatisfaction levels if they do not meet the expectations of users. We demonstrate differences in EHR expectations, preferences, and use among resident and attending physicians, suggesting that within the medical field there are different user characteristics that need to be further dissected and analyzed.

\section{Multiple Choice Question}

Users have distinct EHR personas. Which of the following stages of persona creation is likely to take the most time?
a. Stage I: Gathering data for personas
b. Stage II: Analyzing the data gathered in stage I
c. Stage III: Crafting the actual personas
d. All stages typically take the same amount of time

Correct Answer: The correct answer is option a. Personas are representations of a cluster of users with similar behaviors, goals, and motivations. Personas can be a powerful tool for focusing teams and creating user-centered interfaces because they embody characteristics and behaviors of actual users. However, identifying and creating persona consumes the most time. This stage include empirical research, as well as gathering assumptions and existing insights from stakeholders and other individuals with a deep understanding of target users.

\section{Protection of Human and Animal Subjects}

The study was performed in compliance with the World Medical Association Declaration of Helsinki on Ethical Principles for Medical Research Involving Human Subjects, and was reviewed and approved by the University of North Carolina at Chapel Hill (UNC) Institutional Review Board.

None.

\section{Acknowledgments}

The authors thank Dr. Beth Black, PhD, RN, and Samantha Russomagno, DNP, CPNP for their contribution during manuscript preparation. This study was sponsored by the American Medical Association (AMA).

\section{References}

1 Huerta TR, Thompson MA, Ford EW, Ford WF. Electronic health record implementation and hospitals' total factor productivity. Decis Support Syst 2013;55(02):450-458

2 Cebul RD, Love TE, Jain AK, Hebert CJ. Electronic health records and quality of diabetes care. N Engl J Med 2011;365(09): 825-833

3 Da've D. Benefits and barriers to EMR implementation. Caring 2004;23(11):50-51

4 Walsh SH. The clinician's perspective on electronic health records and how they can affect patient care. BMJ 2004;328(7449): 1184-1187

5 Clayton PD, Naus SP, Bowes WA III, et al. Physician use of electronic medical records: issues and successes with direct data entry and physician productivity. AMIA Annu Symp Proc 2005;2005:141-145

6 Linder JA, Schnipper JL, Middleton B. Method of electronic health record documentation and quality of primary care. J Am Med Inform Assoc 2012;19(06):1019-1024

7 Frisse ME, Johnson KB, Nian H, et al. The financial impact of health information exchange on emergency department care. J Am Med Inform Assoc 2012;19(03):328-333

8 Zhang J, Walji MF. TURF: toward a unified framework of EHR usability. J Biomed Inform 2011;44(06):1056-1067

9 Sittig DF, Belmont E, Singh H. Improving the safety of health information technology requires shared responsibility: it is time we all step up. Healthc (Amst) 2017:S2213-0764(17) 30020-9

10 Tang PC, Patel VL. Major issues in user interface design for health professional workstations: summary and recommendations. Int J Biomed Comput 1994;34(1-4):139-148

11 Linder JA, Schnipper JL, Tsurikova R, Melnikas AJ, Volk LA, Middleton B. Barriers to electronic health record use during patient visits. AMIA Annu Symp Proc 2006;2006:499-503

12 Zhang J. Human-centered computing in health information systems. Part 1: analysis and design. J Biomed Inform 2005;38(01): $1-3$

13 Ratwani RM, Fairbanks RJ, Hettinger AZ, Benda NC. Electronic health record usability: analysis of the user-centered design processes of eleven electronic health record vendors. J Am Med Inform Assoc 2015;22(06):1179-1182

14 Terazzi A, Giordano A, Minuco G. How can usability measurement affect the re-engineering process of clinical software procedures? Int J Med Inform 1998;52(1-3):229-234

15 Association AM. Physicians Use of EHR Systems 2014. Research2015

16 Surgeons AAPa. Physician Results EHR Survey. 2015 8/25/2017. Available at: https://aaps.wufoo.com/reports/physician-resultsehr-survey/. Accessed August 25, 2017

17 Hill RG Jr, Sears LM, Melanson SW. 4000 clicks: a productivity analysis of electronic medical records in a community hospital ED. Am J Emerg Med 2013;31(11):1591-1594

18 Jamoom E, Patel V, King J, Furukawa MF. Physician experience with electronic health record systems that meet meaningful use criteria: NAMCS physician workflow survey, 2011. NCHS Data Brief 2013;(129):1-8

19 McHugh MD, Kutney-Lee A, Cimiotti JP, Sloane DM, Aiken LH. Nurses' widespread job dissatisfaction, burnout, and frustration with health benefits signal problems for patient care. Health Aff (Millwood) 2011;30(02):202-210 
20 Haas JS, Cook EF, Puopolo AL, Burstin HR, Cleary PD, Brennan TA. Is the professional satisfaction of general internists associated with patient satisfaction? J Gen Intern Med 2000;15(02):122-128

21 DiMatteo MR, Sherbourne CD, Hays RD, et al. Physicians' characteristics influence patients' adherence to medical treatment: results from the Medical Outcomes Study. Health Psychol 1993;12 (02):93-102

22 Friedberg MW, Chen PG, Van Busum KR, et al. Factors affecting physician professional satisfaction and their implications for patient care, health systems, and health policy. Rand Health Q 2014;3(04):1

23 Bodenheimer T, Sinsky C. From triple to quadruple aim: care of the patient requires care of the provider. Ann Fam Med 2014;12 (06):573-576

24 Shanafelt TD, Hasan O, Dyrbye LN, et al. Changes in burnout and satisfaction with work-life balance in physicians and the general US working population between 2011 and 2014. Mayo Clin Proc 2015;90(12):1600-1613

25 Hamid F, Cline TW. Providers' Acceptance Factors and Their Perceived Barriers to Electronic Health Record (EHR) Adoption. Online Journal of Nursing Informatics 2013;17(3). Doi: Available at:http://ojni.org/issues/?p=2837. Accessed May 1, 2018

26 Hart SG, Staveland LE. Development of NASA-TLX (Task Load Index): results of empirical and theoretical research. In: Hancock PA, Meshkati N, eds. Advances in Psychology. Los Angeles, California: North-Holland; 1988:139-183

27 Hart SG. NASA-Task Load Index (NASA-TLX); 20 years later. Proceedings of the Human Factors and Ergonomic Society Annual Meeting, 2006;50(9): 904-908

28 Chin JP, Diehl VA, Norman KL. Development of an instrument measuring user satisfaction of the human-computer interface. Proceedings of the SIGCHI Conference on Human Factors in Computing Systems; 1988, ACM: Washington, D.C., USA:213-218

29 AHRQ. Questionnaire for User Interface Satisfaction; 2017. Available at: https://healthit.ahrq.gov/health-it-tools-and-resources/ evaluation-resources/workflow-assessment-health-it-toolkit/ all-workflow-tools/questionnaire. Accessed September 25, 2017

30 Kern LM, Barrón Y, Dhopeshwarkar RV, Edwards A, Kaushal R; HITEC Investigators. Electronic health records and ambulatory quality of care. J Gen Intern Med 2013;28(04):496-503

31 Wachter R. The Digital Doctor: Hope, Hype, and Harm at the Dawn of Medicine's Computer Age. New York, NY: McGraw-Hill Education; 2015

32 Nelson W. The Gimli Glider, in Soaring Magazine; 1997

$33 \mathrm{Ng}$ AKT. Cognitive psychology and human factors engineering of virtual reality. 2017 IEEE Virtual Reality (VR); 2017
34 Singun AP. The usability evaluation of a web-based test blueprint system. 2016 International Conference on Industrial Informatics and Computer Systems (CIICS); 2016

35 Weyers B, Burkolter D, Kluge A, Luther W. User-centered interface reconfiguration for error reduction in human-computer interaction. Presented at: Third International Conference on Advances in Human-Oriented and Personalized Mechanisms. Technologies and Services; August 22-27, 2010; Nice, France

36 Harris D. Human Factors for Civil Flight Deck Design. New York, NY: Taylor \& Francis; 2017

37 Brown DM. Communicating Design: Developing Web Site Documentation for Design and Planning. San Francisco, CA: Pearson Education; 2010

38 O'Connor K. Personas: The Foundation of a Great User Experience; 2011. Available at: http://uxmag.com/articles/personas-thefoundation-of-a-great-user-experience. Accessed March 2, 2018

39 Friess E. Personas in heuristic evaluation: an exploratory study. IEEE Trans Prof Commun 2015;58(02):176-191

40 Gothelf J. Using Proto-Personas for Executive Alignment. UX Magazine; 2012

41 Nielsen J, Landauer TK. A mathematical model of the finding of usability problems. Proceedings of the INTERACT '93 and CHI '93 Conference on Human Factors in Computing Systems. Amsterdam, The Netherlands: ACM; 1993:206-213

42 Duque A, Vázquez C. Double attention bias for positive and negative emotional faces in clinical depression: evidence from an eye-tracking study. J Behav Ther Exp Psychiatry 2015; 46:107-114

43 Pierce K, Marinero S, Hazin R, McKenna B, Barnes CC, Malige A. Eye tracking reveals abnormal visual preference for geometric images as an early biomarker of an autism spectrum disorder subtype associated with increased symptom severity. Biol Psychiatry 2016;79(08):657-666

44 Kassner M, Patera W, Bulling A. Pupil: an open source platform for pervasive eye tracking and mobile gaze-based interaction. Proceedings of the 2014 ACM International Joint Conference on Pervasive and Ubiquitous Computing: Adjunct Publication. Seattle, WA: ACM; 2014:1151-1160

45 Hersh W. Who are the informaticians? What we know and should know. J Am Med Inform Assoc 2006;13(02):166-170

46 Khairat $\mathrm{S}$, et al. A review of biomedical and health informatics education: a workforce training framework. J Hosp Adm 2016;5 (05):10

47 Ajami S, Bagheri-Tadi T. Barriers for adopting electronic health records (EHRs) by physicians. Acta Inform Med 2013;21(02): $129-134$ 
Hart and Staveland's NASA Task Load Index (TLX) method assesses work load on five 7-point scales. Increments of high, medium and low estimates for each point result in 21 gradations on the scales.

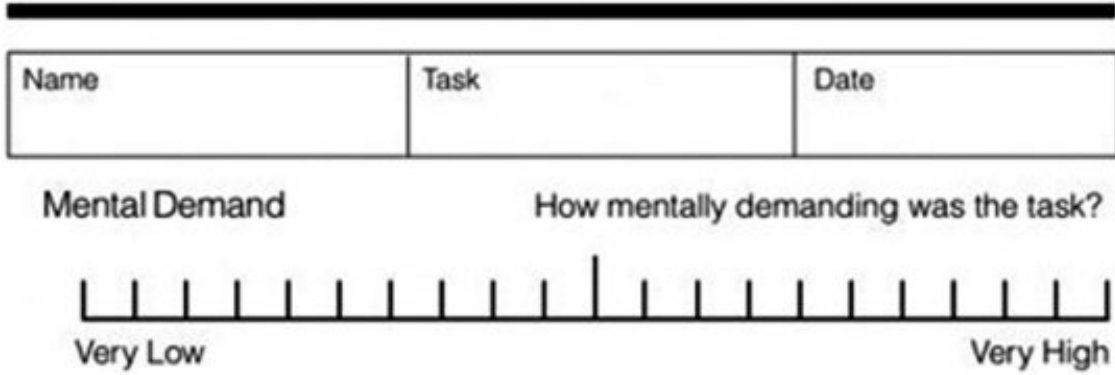

Physical Demand How physically demanding was the task?

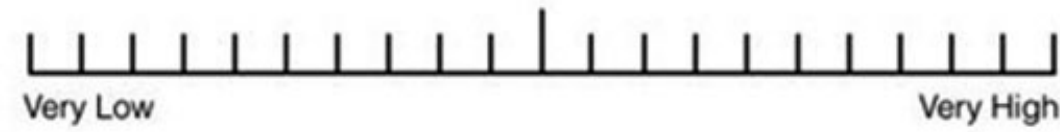

Temporal Demand How hurried or rushed was the pace of the task?

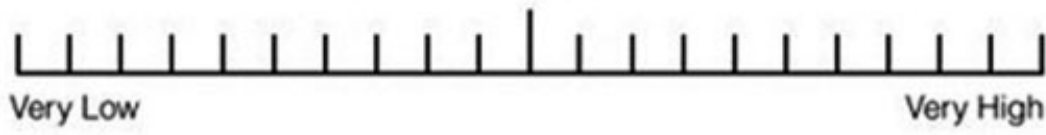

Performance How successful were you in accomplishing what you were asked to do?

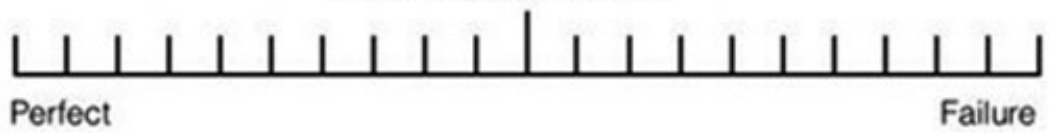

Effort How hard did you have to work to accomplish your level of performance?

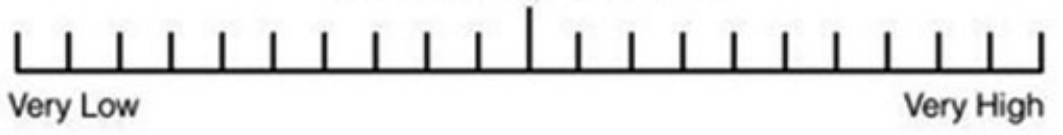

Frustration How insecure, discouraged, irritated, stressed, and annoyed wereyou?

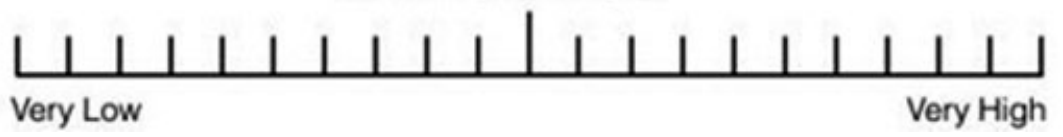

Appendix Fig. A1 NASA-Task Load Index (TLX) used to assess physician's EHR workload. 